artelogie

\section{Artelogie}

Recherche sur les arts, le patrimoine et la littérature de l'Amérique latine

\section{$4 \mid 2013$}

Fêtes et célébrations en Amérique latine

\title{
As Festas da Uva de Caxias do Sul, RS (Brasil) : Historicidade, mensagens, memórias e significados
}

Maria Catarina C. Zanini e Miriam de Oliveira Santos

\section{(2) OpenEdition}

\section{Journals}

Edição electrónica

URL: https://journals.openedition.org/artelogie/5898

DOI: 10.4000/artelogie.5898

ISSN: 2115-6395

\section{Editora}

Association ESCAL

\section{Refêrencia eletrónica}

Maria Catarina C. Zanini e Miriam de Oliveira Santos, «As Festas da Uva de Caxias do Sul, RS (Brasil) : Historicidade, mensagens, memórias e significados», Artelogie [Online], 4 | 2013, posto online no dia 02 fevereiro 2013, consultado o 01 dezembro 2021. URL: http://journals.openedition.org/artelogie/5898 ; DOI: https://doi.org/10.4000/artelogie.5898

Este documento foi criado de forma automática no dia 1 dezembro 2021.

Association ESCAL 


\title{
As Festas da Uva de Caxias do Sul, RS (Brasil) : Historicidade, mensagens, memórias e significados
}

\author{
Maria Catarina C. Zanini e Miriam de Oliveira Santos
}

1 Nosso objetivo nesse artigo é apresentar e analisar elementos presentes na Festa da Uva que ocorre bianualmente na cidade de Caxias do Sul ${ }^{1}$, no estado do Rio Grande do Sul (Brasil). Para entender a Festa da Uva e as mensagens por ela transmitidas desde 1931 é necessário retroceder no tempo e examinar a história de Caxias do Sul e da própria festa em suas várias edições. A Festa teve seu início no ano de 1931, acontecendo meio século após a chegada dos primeiros imigrantes italianos para a região (em 1875). Naquele momento, ela buscava representar e demarcar distintividades e especificidades culturais de uma população de emigrados que já estavam estabelecidos na região e que tinham nas videiras um forte potencial produtivo e fonte de renda. Tinha, igualmente, como alertavam seus organizadores, uma função pedagógica junto aos colonos vitivinicultores que queriam continuar plantando somente a variedade de uva Isabel $^{2}$ que, segundo especialistas, não produzia os melhores vinhos. Por colonos se entende aqui aqueles camponeses imigrantes e seus descendentes que haviam recebido lotes nas colônias. E que, como ressalta Seyferth (1993), reivindicam uma origem diferenciada da população nacional. No caso aqui analisado, a origem italiana derivada do processo migratório de seus antepassados.

Entendemos que, por mais diversas que tenham sido historicamente as Festas da Uva (de 1931 até os dias atuais) e as formas de festejar por meio dela, um dos elementos importantes a ser ressaltado é seu caráter de festa da ordem (DA MATTA, 1993), ou seja, como um momento no qual as relações sociais e suas hierarquias são expostas, mantidas e, muitas vezes, reforçadas. ${ }^{3} \mathrm{Na}$ Festa os valores dos imigrantes italianos e seus descendentes se expressam englobando outras diversidades culturais e sociais existentes na cidade e observamos que a marca maior da festa é o valor atribuído ao trabalho e ao que dele deriva (fartura, riqueza, família unida, entre outros valores). Trata-se não somente de uma festa na cidade de Caxias do Sul, mas de uma festa da 
cidade de Caxias do Sul (TEIXEIRA, 1988). Ela é também, como aponta Ribeiro (2002, p.21), uma festa educativa, que reatualiza a coisa celebrada, ou seja, o processo migratório e colonizador dos antepassados e suas construções. Desta forma, entendemos a Festa como uma potente ferramenta mnemônica que possibilita atualizações constantes acerca das origens italianas dos caxienses. Por meio dela memórias são atualizadas e novas narrativas elaboradas, permitindo a constante partilha coletiva de significados. Por memória entendemos, conforme Halbwachs (1990), as construções acerca do passado elaboradas no presente. As Festas da uva, em suas várias edições, foram e são partilha de tempos e espaços e também de exaltação à italianidade e seus atributos.

3 A imigração de famílias italianas para o Brasil se processa dentro de um contexto internacional para o qual contribuem o capitalismo tardio da Itália, a necessidade brasileira de povoar a região sul e de buscar alternativas para a utilização da mão de obra escrava, entre outros fatores. Havia, tanto por parte do governo brasileiro, como do estado italiano, interesse neste processo migratório. Os italianos do norte da Itália eram brancos, latinos, católicos, considerados dóceis e bons trabalhadores, o que favorecia sua aceitação em terras brasileiras. Por outro lado, interessava ao Estado Italiano se livrar de uma grande massa de população pobre e com pouca escolaridade.Em 1875 chegaram ao estado do Rio Grande do Sul (no sul do Brasil) as primeiras famílias vindas da Itália. Caxias do Sul foi a primeira das quatro colônias de imigrantes italianos instaladas no Rio Grande do Sul. ${ }^{4}$ Nestas colônias vigorou o sistema da pequena propriedade familiar, contudo eram núcleos que também possuíam lotes urbanos e uma distribuição espacial que contribuía para a auto-suficiência local. Estes primeiros imigrantes eram, em sua maioria, provenientes do Norte da Itália (venetos, lombardos, friulanos e trentinos). Majoritariamente católicos, camponeses e pobres, vislumbravam na emigração para a América uma oportunidade de ascender socialmente, bem como reproduzir a condição camponesa como proprietários, pois no Brasil poderiam comprar lotes de terra pagando-os ao longo dos anos. Consideramos importante salientar também que compreendemos a emigração italiana do período como um esforço de sobrevivência cultural (vide ALVIM, 1986 e GROSSELLI, 1987) para famílias camponesas que viam na Itália do período uma ameaça aos valores da catolicidade e da família camponesa, baseada na autoridade paterna. Pode-se dizer que a Igreja Católica também migrou. Chegando aos poucos, foi assumindo seu papel junto às colônias de emigrados, difundindo seus valores e suas configurações de mundo, baseadas na família e na disciplina para o trabalho. Para De Boni (1980), o idioma comum dos primeiros imigrantes italianos era a catolicidade, característica que possibilitou uma coesão entre eles. Ao emigrarem, nem todos se sentiam italianos, visto que a unificação italiana iniciada em 1870 ainda não estava suficientemente consolidada. Identificavam-se com seus paese de origem (lugares de origem). Eram populações que falavam distintos dialetos, adoravam santos específicos e tinham uma vivência diferenciada da Itália de origem. Foi a emigração e os diferentes processos que enfrentaram na travessia e no processo colonizador no Brasil que foram tornando aquelas populações em italianos (ZANINI, 2006). No confronto e convívio com os brasileiros a identidade de italianos começa a emergir e fazer sentido.

4 Na região de Caxias do Sul, por meio da conversão do capital agrícola em industrial, do apoio dos governos estadual e federal, da chegada da ferrovia e de uma economia que se baseava no trabalho como um valor (vide ZANINI e SANTOS, 2009), o desenvolvimento e enriquecimento chegaram. As relações entre a colônia italiana e as forças regionais 
acontecem pacificamente e as cooperações mútuas favorecem a dinamização da economia local. Contudo, há, igualmente, momentos tensos na relação destas populações com a sociedade brasileira, especialmente no período do Estado Novo (1937-1945) e posteriormente durante a II Guerra Mundial (1939-1945). No contexto político conflitivo da II Guerra Mundial, japoneses, italianos e alemães foram perseguidos (DALMOLIN, 2005; ZANINI, 2006, SGANZERLA, 2001). Tendo o Brasil entrado na II Guerra Mundial, lutando contra o Eixo, formado por Itália, Japão e Alemanha, os descendentes destes grupos aqui habitantes foram compreendidos pelo governo brasileiro com "perigos", especialmente após 1942. No estado do Rio Grande do Sul, principalmente em função do grande número de imigrantes e descendentes, houve prisões e repressões públicas a indivíduos que teriam desacatado ordens ou simplesmente por que estavam falando em italiano ou expressando idéias que poderiam ser consideradas antipatrióticas. Segundo Beneduzi (2011), em Caxias havia uma simpatia à figura do Duce (Benito Mussolini), o que fez, em nossa compreensão, com que este silenciamento fosse estratégico. 0 mesmo autor afirma que esta simpatia estaria presente também na Festa da Uva.Após este período repressivo, houve certo apagamento de manifestações mais públicas das vivências da origem italiana e também de culto à italianidade. Há que se ressaltar também que a legislação do Estado Novo proibiu o uso dos dialetos e da língua italiana, das formações associativas e do exercício de outros modos de sociabilidade, inclusive religiosas. De 1938 a 1949 a Festa da Uva não acontece, dialogando com a tensão daquele momento histórico. Em 1950 a Festa da Uva retorna com pompa e após 1975, quando dos festejos do centenário da imigração italiana para o estado, haverá, em nível regional, um renascimento das italianidades e das expressões de pertencimento ao mundo de origem (italiano).

\section{A Uva e sua Festa : Vinde ver o que somos e o que valemos $^{5}$}

O cultivo de uva se intensificou na Serra Gaúcha, transformando-se, em poucos anos, na principal fonte de riquezas da região. Os imigrantes e seus descendentes produziam vinho e começaram a vendê-lo para outras regiões do Rio Grande do Sul e mais tarde passaram a abastecer também São Paulo e Rio de Janeiro. Conscientes de que a Isabel, variedade cultivada na região principalmente em função da sua resistência às pragas, não era a espécie de uva ideal para a produção de vinhos de melhor qualidade, as autoridades colocaram à disposição dos viticultores outras variedades viníferas. Estas modificações, contudo, não foram bem aceitas pelos os colonos que temiam o cultivo de variedades de uva que pudessem não se ambientar à região ou apresentar pragas desconhecidas. Em 1913 foi criada, em Caxias do Sul, a Estação Experimental, sua atribuição era descobrir que culturas agrícolas eram mais viáveis na Serra Gaúcha, mas com o tempo, a Estação acabou especializando-se na produção de variedades finas de uvas, ideais para a produção de vinho. $O$ problema maior, contudo, era convencer os produtores a deixar de plantar a uva do tipo Isabel e optar pelas variedades novas. Em 1928, com o objetivo de regular a produção e melhorar a qualidade da uva, as cantinas criaram o Instituto Riograndense do Vinho, órgão que reunia apenas as indústrias. Estimulados pelo governo, os viticultores formaram várias cooperativas em 1929. No dia 8 de março de 1931 foi realizada, no Clube Juventude, localizado na cidade de Caxias do Sul, a primeira Festa Nacional da Uva. Foi organizada por Joaquim Pedro Lisboa, um 
coletor estadual de impostos e membro do Instituto do Vinho, com o objetivo de melhorar a qualidade do vinho produzido na Serra Gaúcha. Para a realização deste evento, teriam contribuído também o diretor da Estação Experimental Celeste Gobbato, os governos municipal e estadual. Na verdade, esta primeira Festa da Uva, que aconteceu em um dia somente, foi uma exposição de uvas diversas e uma tentativa de convencer aos colonos que outras variedades viníferas poderiam ser cultivadas com sucesso na região. Além disto, em todas as edições da Festa houve a presença de autoridades importantes, o que salienta o papel que as festas desempenham como catalisador e fomentador de capital social para a cidade. Os visitantes importantes eram extremamente bem atendidos e a cidade e suas potencialidades eram exibidas ao máximo.

6 A Segunda Festa da Uva foi realizada em 28 de fevereiro de 1932 na Praça Dante Alighieri, no centro de Caxias do Sul. Nesta edição houve desfile na cidade e a construção de um chafariz do qual jorrou vinho durante os oito dias de duração da festa (ERBES, 2000, p. 27). Em 1933, ainda na Praça Dante Alighieri é realizada a Terceira Festa da Uva, reunindo as três principais características que marcariam a festa desde então : o produto (a uva), o corso alegórico e a eleição da rainha. Aliás, a escolha das rainhas da Festa da uva é algo que também narra um pouco da festa, das negociações políticas ali presentes e qual tipo de descendente de italiano seria o ideal a ser representado publicamente nas situações festivas. Além disto, a festa da uva por ser observada com uma festa dos sentidos também e a beleza feminina, com certeza, reforçaria esta associação. Segundo Silva (2011), os destaques nas fotografias eram sempre para as rainhas e princesas, que apareciam junto às autoridades. Segundo a autora, nestas fotografias, a imagem da mulher seria usada como ornamento (idem,p.5). Na edição de 1933, a rainha eleita foi Adélia Eberle, com 5.934 votos. Adélia era membro de importante família local. A eleição da Rainha era uma promoção do jornal $O$ Pioneiro de Caxias do Sul e para votar era necessário comprar o jornal e recortar o cupom que vinha impresso no mesmo (SANTOS, 2004).Em 1934, a rainha foi Odila Zatti que, da mesma forma que a primeira rainha, pertencia à elite local. A associação da uva com a mulher é uma constante nas festas. Terra, fartura e feminino se entrelaçavam nas construções discursivas para as rainhas e sobre a Festa. Em 1937 acontece a V Festa da Uva, contudo sem a escolha da rainha, mas com o desfile de carros alegóricos. Depois deste ano, a Festa somente volta a acontecer em 1950. Esta interrupção ocorre em função dos fatos políticos daqueles anos : Estado Novo e seu processo de nacionalização e a II Guerra Mundial. Em 1950, em campanha presidencial, Getúlio Vargas comparece na abertura da Festa, que passa a ocorrer de quatro em quatro anos. Em 1954 recebe espaço próprio, no lugar em que atualmente funciona a prefeitura de Caxias do Sul. Neste ano, a rainha eleita é Maria Elisa Eberle (sobrinha de Adélia, rainha de 1933), que recebe o seguinte discurso na proclamação de seu reinado :

...No simbolismo de um reinado que se exercerá durante esta grande exaltação do trabalho de nossa gente, estais destinada a ser, pela escolha que hoje se conclui, também a chama votiva que conduzirá os nossos espíritos para o alto, onde se situam as lembranças queridas daqueles que nos antecederam nas lutas que estamos empreendendo, em todas as horas e em todos os momentos, para tornar mais grandioso o patrimônio que, com sacrifício heróico e trabalho ingente, nos foi, pelo menos, legado.Nas anteriores festas desta natureza, enaltecemos o trabalho dos coevos; nesta vamos glorificar também o trabalho, muito mais importante porque mais duro e porfiado, daqueles que desbravando a selva aqui fizeram rutilar 
as primeiras almenares do progresso (Artur Rodolfo Rossarola, in História da Festa

da Uva, 1991, p. 24)

7 A participação das rainhas vai tomando importância e elas se tornam as porta-vozes da festa em nível regional e nacional. Por meio delas e também com elas, há todo um capital social que se forma em torno da festividade. Na edição de 1968 a rainha eleita ganhou um carro, salientando a importância de tal função para a Festa. Há, também, em nível local, disputas e torcida para as candidatas. Contemporaneamente, ser rainha da Festa da Uva ainda é um importante distintivo para as moças residentes em Caxias.

8 A partir de 1954, a Festa da Uva, que se encontrava em sua sétima edição, dá início conjunto à I Feira Agro-industrial que passava a acontecer simultaneamente. A origem da indústria caxiense teve seu desenvolvimento em 1895 com a atuação de Abramo Eberle um jovem italiano de 16 anos que inicia uma pequena funilaria. Ainda hoje as indústrias Eberle têm participação destacada na economia do município e suas ligações com a Festa da Uva remontam aos primórdios da mesma. Duas das rainhas da Festa da Uva (Adélia, de 1933 e sua sobrinha Maria Elisa Eberle, em 1954) eram membros da família Eberle. Caxias do Sul constitui atualmente, o 2o. maior e mais influente município do Rio Grande do Sul. A região é importante pólo de fabricação de vinhos, móveis, autopeças, carrocerias, malhas e outros produtos e serviços. A cidade de Caxias do Sul se destaca em várias áreas de atuação, sendo sede de importantes empresas do setor metal-mecânico, como Marcopolo, Randon, Frasle, Soprano, Enxuta, Agrale, Caminhões International e outras. Acreditamos encontrar aqui uma característica bastante interessante da Festa da Uva, apesar de ser uma típica festa da colheita, ela acontece em uma área urbana e industrial, tendo tido em várias edições um espaço privilegiado para as exposições industriais, o que desgostava alguns setores que observavam na mesma mais um caráter de feira do que de festa. No ano de 1978, para as festividades, é construída na área do parque de exposições uma réplica da cidade de Caxias no ano 1885. Nesta foram construídas 20 casas e 1 igreja. Esta materialização do passado é muito interessante de ser observada, pois atesta a importância de um espaço em que as origens podem e devem ser mostradas espacialmente para locais e turistas. 


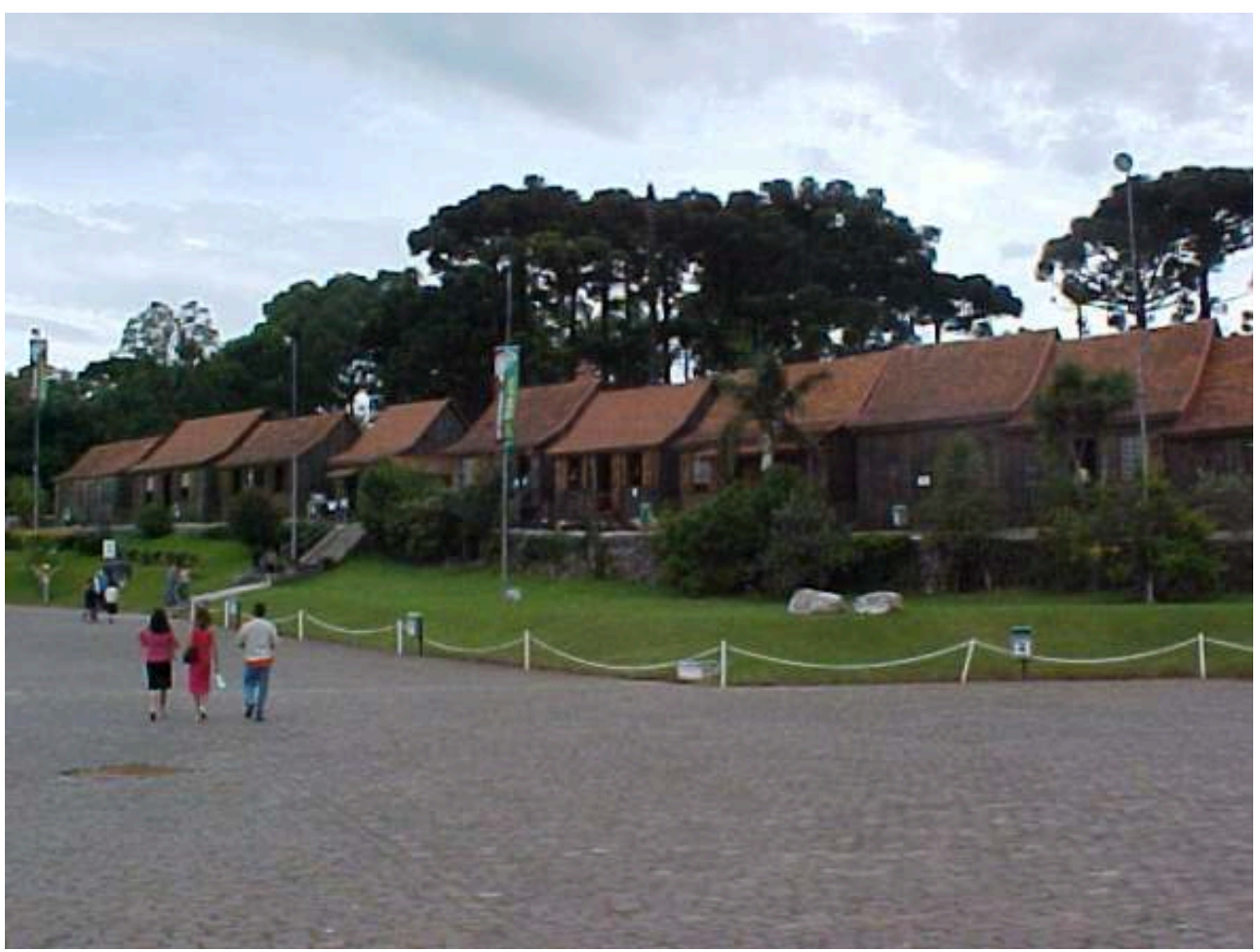

Miriam de Oliveira Santos, 2002

Segundo Ribeiro (2002, p. 22-23), a existência Festa da Uva pode ser dividida em momentos: o primeiro, na década de 30, com seu nascimento; o segundo, que começaria na Festa da Uva de 1950, após os acontecimentos da II Guerra Mundial ; o terceiro, partindo das comemorações do centenário da imigração italiana, em 1975, quando começa a haver conflitos entre uma visão mais tradicional da festa e os interesses econômicos que a direcionavam; e, o quarto momento, a partir de $1992 \mathrm{e}$ 1994, quando a festa começa a ter um caráter mais comunitário. Importante ressaltar que em 1985 a Universidade de Caxias do Sul (UCS) se manifesta com idéias e propostas para trazer de volta as comunidades locais para a festa (ERBES, 2000, p.100). Observamos ai a inclusão na organização da festa da elite intelectual que vem se somar a elite política e econômica que predominavam até então, nesse momento também começa a haver um apelo ao politicamente correto e uma discussão sobre como tornar a festa mais popular. Dos quatro períodos distintos da Festa da Uva, o mais rico em mensagens é sem dúvida alguma o segundo, quando a Festa aparece como uma demonstração do orgulho de ser italiano e da força do imigrante, apesar das perseguições ocorridas durante a II Guerra Mundial. Sendo assim, a presença de Getúlio Vargas na cidade para assistir à Festa de 1954 e para inaugurar o monumento ao Imigrante é reinterpretada como um pedido de desculpas aos imigrantes italianos pelas perseguições que estes sofreram durante a II Guerra Mundial.Como um fenômeno comunitário ou coletivo, a festa permeia toda a sociedade Caxiense, significando uma trégua no cotidiano rotineiro e na atividade produtiva. Por meio de seus corsos, carros alegóricos, cartazes, discursos, o que se observa é uma exaltação ao trabalho e à cultura italiana. Como apresenta Zottis (2009), os cartazes da Festa da Uva que, muitas vezes, eram mais de um por edição, apresentavam os elementos marcantes da cidade e 
circulavam por vários municípios.Desta forma observamos que, como assinala Maynard Araújo (1973, p. 11) :

A festa interrelaciona-se não só com a produção, mas também com os meios de trabalho, exploração e distribuição, ela é portanto conseqüência das próprias forças produtivas da sociedade, por outro lado é uma poderosa força de coesão grupal, reforçadora da solidariedade vicinal cujas raízes estão no instinto biológico da ajuda, nos grupos familiares.

11 No caso específico da Festa da Uva, podemos destacar que inicialmente, ela se apresenta como catalisador para o grupo imigrante, contribuindo para a coesão grupal, para o envio de mensagens edificantes e de sinais diacríticos que distingam o grupo imigrante da sociedade nacional que o rodeava. $\mathrm{Na}$ década de 50 , quando era organizada principalmente pela elite industrial, contribui também para criar operários diligentes e dóceis por meio das mensagens emitidas.Contudo, a expansão de Caxias do Sul e o crescimento da população que vem de outras regiões atraída pela expansão da indústria determinaram certa confusão na emissão das mensagens da Festa. Nos meios oficiais encarregados da organização da Festa existe a percepção que ela passou e passa por uma crise. Se, por um lado, a festa se tornou um evento nacional, consolidado no calendário turístico do estado e com destaque na mídia regional e nacional, por outro perdeu a espontaneidade, a participação dos membros da população e se transformou historicamente cada vez mais em uma exposição agropecuária (em feira). Uma das novidades da Festa da Uva de 2002 sinalizava justamente para a tentativa de retorno as origens. $\mathrm{O}$ encarregado da Exposição Agro-Industrial (que aconteceu junto com todas as edições da Festa da Uva) foi, não um industrial, mas o presidente do Sindicato Rural de Caxias do Sul. Sobre a região de Caxias do Sul, é importante observar o que nos diz Thales de Azevedo, que lá realizou uma longa pesquisa de campo :

Caxias é uma zona rural que enriqueceu e se vai transformando, rompendo a unidade da área. Persistem ali valores da zona rural que os 'ítalos' supõem europeus, mas que são apenas 'coloniais', isto é, reelaborações da experiência européia no meio colonial (AZEVEDO, 1994).

12 Como já salientamos anteriormente, a Festa da Uva de Caxias do Sul se enquadra no que Roberto da Matta (1993) chamou de festas da ordem, atribuindo-lhes a função de sedimentar as diferenças e gradações sociais, apontando e conservando hierarquias e poderes. ${ }^{6}$ No caso específico de Caxias do Sul, celebra-se uma vitória do trabalho do imigrante sobre a terra hostil. Neste ponto é bastante ilustrativo o lema da Festa da Uva de 1996 A América que nós fizemos.

\section{Os significados das Festas da Uva : trabalho, riqueza, italianidade e o importante papel das mídias}

13 Como já observado, a Festa da Uva foi uma Festa inicialmente pensada para o convencimento dos produtores acerca da possibilidade de produzirem melhores vinhos por meio do plantio de variedades novas de uva. Contudo, ao longo do tempo se tornou uma vitrine da colônia italiana e do que esta produzia, muito além de uvas e vinhos. Neste sentido, tem sido uma Festa de Produção e também de celebração de uma origem comum, sendo organizada e pensada como distintiva pela elite da colônia. É importante salientar que já em 1931, quando do início da Festa da Uva, Caxias possuía uma estratificação social demarcada : colonos, empresários, comerciantes, uma classe média 
de funcionários públicos, entre outros segmentos diferenciados. A Festa, em todas as suas versões, sempre foi organizada e/ou presidida por membros pertencentes ou representantes da elite local, italianos e não italianos. Contudo, apesar destas distinções, há valores que são comuns e que estão presentes em todas as versões da festa. O maior deles, com certeza é o do trabalho. Na primeira edição, de 1931, este já é um demarcador: ...Esta festa, como todas aquelas que visam á glorificação do trabalho, contribuirá, sem dúvida, para o melhoramento da produção de uva (in ERBES, 2000, p.13). 0 trabalho, a fartura, o passado colonizador, o presente de desenvolvimento são temas sempre recorrentes nas várias edições das festas.

Desfile 2002

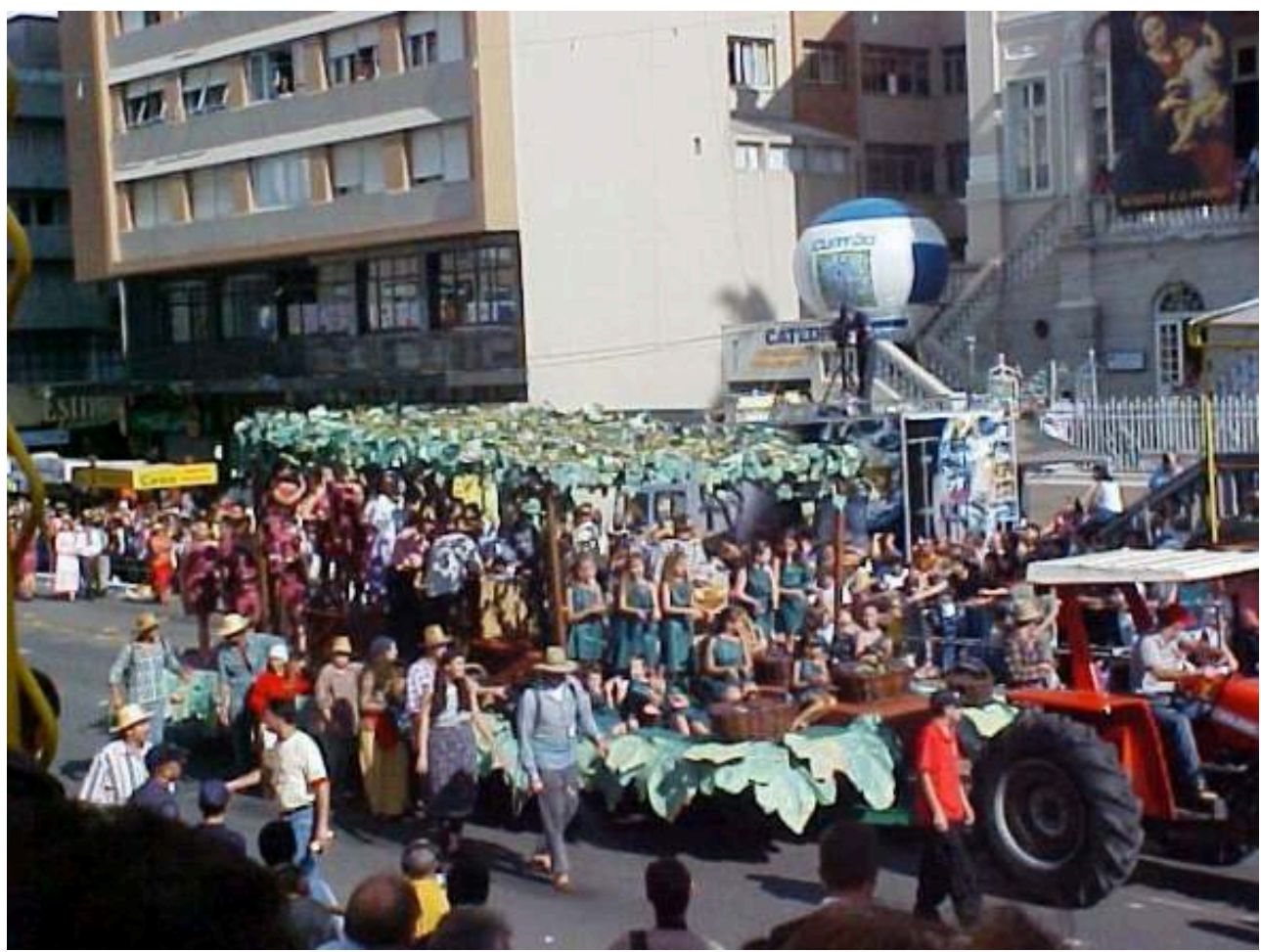

Miriam de Oliveira Santos, 2002

14 É importante ressaltar que como todas as festas tradicionais que sobreviveram a Festa da Uva precisou se adaptar aos novos tempos, incorporando outros códigos em sua organização estrutural, códigos estes que são resultante de vários fatores. A Festa foi, ao longo de suas edições, passando por crises financeiras e problemas de gerência. Em 1974 foi criada a empresa Festa Nacional da Uva, Turismo e Empreendimentos S.A. com a participação da Prefeitura Municipal de Caxias do Sul, CRTUR do Estado, Embratur, Banrisul, Mitra Diocesana, entre outros, sendo hoje a Prefeitura Municipal de Caxias do Sul a acionista majoritária, com $72 \%$ das ações. O principal objetivo da empresa era a realização da Festa da Uva. Em 1975, no centenário da imigração italiana, foram inaugurados os atuais pavilhões do Parque de Exposições Centenário. Ao longo do tempo a periodicidade da festa se alterou, passando de anual para quadrienal, trienal sendo atualmente bienal (desde 1994).

Uma festa continuada no tempo é como um organismo vivo, que vai se transformando aos poucos, no caso da Festa da Uva influi especialmente a profissionalização da sua 
organização e ainda o grande crescimento urbano de Caxias do Sul. Ao longo das edições, alteram-se os organizadores e as mensagens, e estas mudanças produzem seus reflexos na festa. A profissionalização acontece particularmente após a fundação da empresa Festa da Uva S/A (1974), especialmente para a organização da Festa, apesar de continuar havendo uma comissão comunitária, escolhida entre os notáveis da cidade com o mesmo fim.

Neste contexto, é possível observar a Festa da Uva de Caxias do Sul, como um espaço social nos termos propostos pelo mexicano Jorge González (1994, p. 82) :

(...), entrecuzamentos e formas de relações sociais não especializadas, onde luta ou se vem lutando pelo monopólio legítimo da construção e reconstrução semiótica (modulação e modelação) de determinados elementos culturais transclassistas (GONZÁLEZ,1994, p. 82).

17 Na Festa da Uva de 2002, por exemplo, o tema foi A Mulher (I)migrante, o que visava evidentemente destacar não só as mamas e nonnas da imigração italiana, mas também aquelas novas migrantes que acorrem para Caxias do Sul em busca de emprego, já que a cidade se destacava cada vez mais pelo seu crescimento industrial. A festa tem, ao longo de suas edições, tentando se abrir à diversidade local. Contudo, o grande personagem ainda é o imigrante italiano, seus descendentes e as realizações destes.Nas festas populares, as classes sociais interagem dialeticamente, coexistindo de forma aparente, mas na verdade enfrentando-se, ora sutil, ora de modo ostensivo, na tentativa de conquistar a hegemonia cultural. Em Caxias, observamos inicialmente uma luta pela hegemonia cultural entre a elite oriunda da imigração italiana e outras elites locais. Uma ilustração deste processo é o que ocorre com a construção do monumento ao imigrante em 1954, quando há sugestões por parte do representante da sociedade local, militar e sem origem italiana que se coloque no monumento além dos nomes das famílias que imigraram para a região, o nome dos soldados de Caxias do Sul que morreram na II Guerra Mundial. Sua sugestão é rapidamente descartada e considerada totalmente despropositada (SANTOS,2004).

Atualmente, as antigas tradições vão sendo substituídas por novos padrões de interação sócio-cultural. A mídia e as instituições comerciais transformam as festas em espetáculos coletivos, fruídos por usuários dispersos que observam na festa um momento de descontração e lazer. Já na edição de 1972, a Festa mostrava sua vocação e diálogo com as mídias, sendo a Festa da uva a primeira transmissão de televisão em cores no Brasil. Este acontecimento projetou a cidade e a festa em nível nacional. 
Carpinteiro

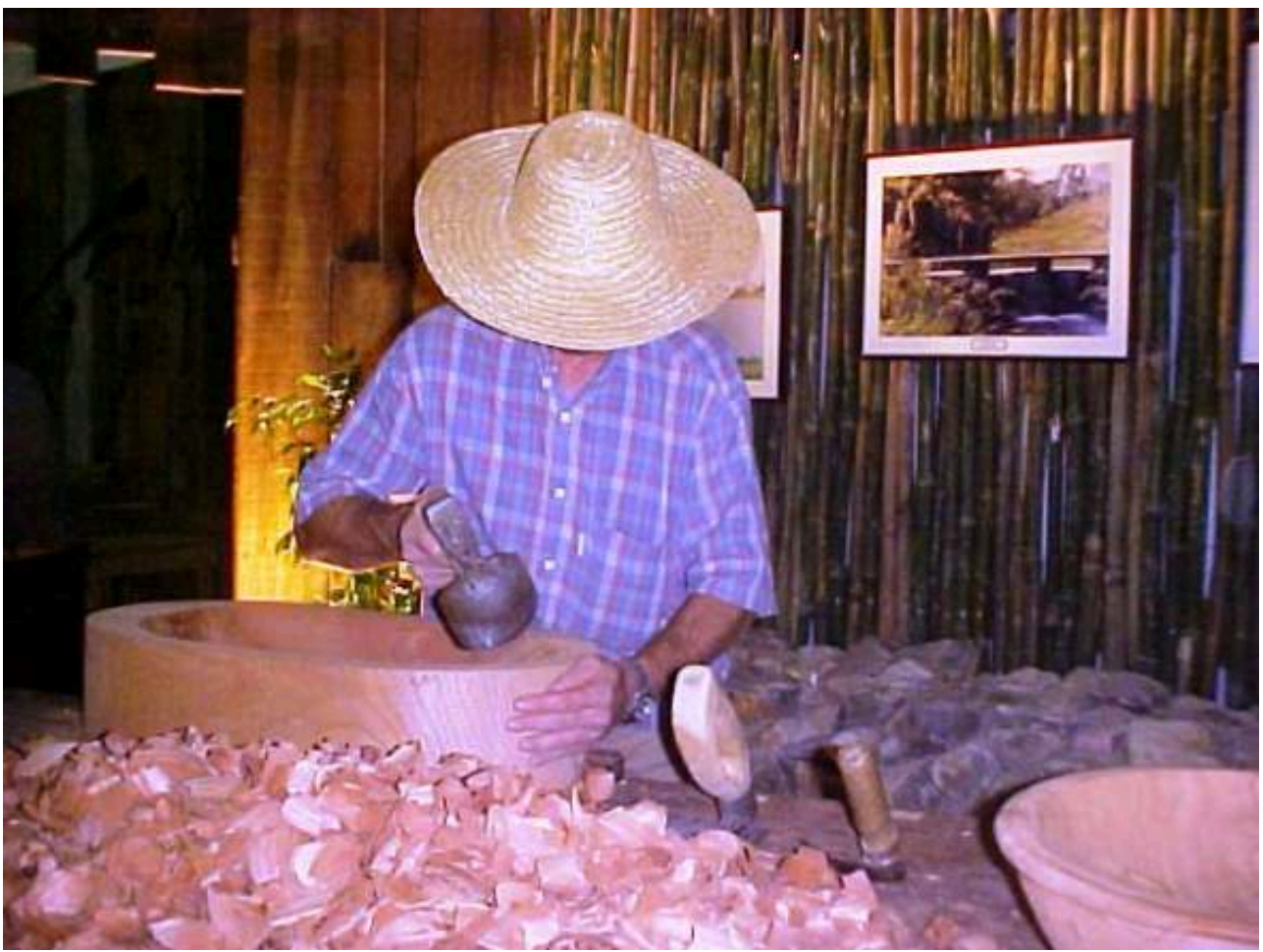

Miriam de Oliveira Santos, 2002

A cobertura da RBS (Grupo Rede Brasil Sul), emissora regional e do Jornal 0 Pioneiro pertencente ao mesmo grupo, enfatiza bastante o concurso para a escolha da rainha da Festa da Uva, ao mesmo tempo em que ressalta o elemento comum e unificador da Festa, com expressões como : nosso estado, nossa tradição, e ainda várias entrevistas de turistas de outros estados brasileiros em que é ressaltado que : Nem parece que estamos no Brasil.

Segundo Schleder (2009), desde a década de 90, há uma preocupação, em nível local, para reaproximar a comunidade da festa. Em estudo por ela efetuado no jornal local $O$ Pioneiro $^{7}$ de 1994 a 2008, observou que a população tem interesse em se manifestar acerca da Festa no espaço dos leitores. Ela contabilizou 279 notas. A festa é, igualmente, amplamente noticiada no jornal, tornando-se um evento catalisador dos interesses locais. Espeiorin e Pozenato (2010), ao analisarem a importância do jornal $O$ Pioneiro para a cidade de Caxias, ressaltam que este é um elemento importante para a criação de um discurso de integração social local por meio da Festa.Este grande apoio da mídia de Caxias do Sul e do Estado é impulsionado graças, também, ao orgulho que o gaúcho tem das coisas de seu estado e de suas origens. Aparece ai uma dupla inserção: são descendentes de imigrantes italianos e também gaúchos. Em resumo: são ítalos-gaúchos. A festa tem um valor conteudístico, preenchendo espaços na programação das emissoras de rádio e TV, e ainda motivando reportagens e coberturas especiais nos jornais diários, tanto de Caxias do Sul, quanto da capital, Porto Alegre. Ao mesmo tempo, a Festa da Uva funciona como um vigoroso impulso, não só para o setor turístico da cidade, mas ainda como vitrine para a sua produção agro-industrial. Cria-se uma teia complexa de relações e interesses, da qual participam também o Estado e o aparato político, responsáveis pela normatização do uso do espaço público no qual a 
festa se realiza. Aliás, a importância da mídia sempre esteve presente nas edições da Festa da Uva, quando noticiavam a presença de autoridades estaduais e nacionais, além de exaltarem as virtudes dos colonizadores da região, a cidade aparecia como uma vitrine de progresso. Na edição de 1932, do Correio do Povo, jornal de Porto Alegre, era publicado:

...Eis, aí, aos vossos olhos, a cidade que, há cinquenta anos, o italiano de mãos e plantas nuas jogou no cimo da serrania brava do Rio Grande e hoje, por seus filhos, oferece como jóia rara no engaste verde de uma paisagem de pinheiros, à vida e á glória do Brasil. Quem não a conhece, não conhece ainda o Rio Grande do Sul... a cidade, amorosa da sua colônia e do sue povo, realiza agora um grande sonho : o trabalho longo e penoso fez o milagre da fartura. Do chão árido brotaram vinhedos agarrando-se às encostas. $\mathrm{E}$, deles, em caudais de sangue generoso que alenta $\mathrm{e}$ vivifica, dos morros desce o vinho a inundar a planície de saúde e de riqueza. Por isso a grandiosidade desta festa. É a consagração do trabalho (Correio do Povo, Porto Alegre, p. 2, mar.1932, apud RIBEIRO, 2002, p. 95)

21 Ao longo de suas edições, foi do interior da sociedade civil que se desencadearam os processos de celebração que nutrem e fortalecem a festa continuadamente. É a iniciativa dos grupos sociais organizados que dão sentido, codificam, difundem e retro-alimentam as mensagens contidas na Festa da Uva. Ou seja, as mensagens presentes na Festa são partilhadas coletivamente e possuem significados legitimados. $O$ maior deles, como já salientamos, seria o trabalho e a produção de riqueza por meio deste.Podemos nos alinhar com o pensamento de Araújo $(1996$, p. 61) e apontar a existência de uma continuidade histórica, resultante de uma comunidade de sentido inerente à sociedade :

Eles sugerem a existência de uma certa continuidade e regularidade que relacionaria um tempo histórico a outro, o passado ao presente. $\mathrm{E}$ o fazem exatamente ao revelar a existência de um fundo cultural comum, de uma comunidade de sentido na qual uma determinada sociedade cria e recria suas práticas, temas símbolos, mitos e outras expressões coletivas.

O conteúdo da festa em questão está relacionado à imigração italiana e ao orgulho e identidade étnica, mas também a idéia de progresso e da vitória do trabalho, que transcende tais origens (vide MONTEIRO, 2012). Os textos dos convites para as festas falam muito sobre a valorização do trabalho, e especialmente do trabalho do imigrante italiano. O tempo todo, em todos os locais em que se desenrola a Festa, mas especialmente nos desfiles e nos discursos, exalta-se o colono italiano, o pioneiro fundador da cidade de Caxias do Sul e suas realizações. A festa pode ser observada, desta forma, como uma celebração da civilização trazida pelos imigrantes e a riqueza por eles produzida. Ela mostra e exalta a civilização.Sobre esta valorização da identidade italiana o seguinte trecho retirado de um folheto turístico sobre Caxias do sul é bastante ilustrativo :

Caxias do Sul é hoje, o pólo centralizador da região mais diversificada do Brasil, com seus laboriosos colonos, seus vastos parreirais, suas vinícolas, seu variado parque industrial e um comércio rico e dinâmico ; dando a esta terra uma dimensão ainda maior, razão essa que 'Caxias do Sul', a 'Capital da Montanha', a 'Pérola das Colônias', a 'Colméia do Trabalho' é, por si só, o pólo centralizador da marca italiana no sul do Brasil (SANTOS,2004).

As atividades ligadas ao enoturismo na região, com a formatação do Vale dos Vinhedos, por exemplo, é também uma forma de potencializar o que a Festa da Uva também tem feito : salientar positivamente os valores dos imigrantes italianos e seus descendentes. Segundo Frigeri (2009), há, na região, uma forte ligação entre vinho, italianidade e 
turismo. Fazer dela negócio e transforma-la em algo possível de ser produto no mercado é uma conseqüência.

\section{Considerações Finais}

Não se pode esquecer que a Festa sempre foi um momento em que as autoridades locais negociavam interesses com as autoridades regionais e nacionais. Era por meio da festa que acordos e colaborações aconteciam. Sendo assim, para além do que foi salientado até o momento, é importante apontar que a festa é um espaço político por excelência. Nela, como num mercado, muitas negociações acontecem.

A Festa da uva, como apresentado neste artigo, foi desde 1931 e ainda é um acontecimento para a cidade de Caxias do Sul. É a festa do lugar, de seus habitantes, de sua historicidade. Marcada por hierarquias e disputas por poder, a festa também representa a dinâmica dos interesses locais. Ela não está insenta de contradições e de negociações. Aliás, a festa é negociação pura : de sentidos, de mercados, de poderes e representações de mundo. Por mais que a população da cidade tenha se diversificado ao longo de sua história por meio de migrações de trabalhadores do interior do estado do Rio Grande do Sul, bem como de todo o país, a marca da festa continua a ser a italianidade e o trabalho a ela associado.

Por mais que as populações que cheguem à cidade sejam diferenciadas, o trabalho como demarcador local é prontamente assimilado (Monteiro, 2012), possibilitando e favorecendo com que haja uma identificação com os valores propostos pela Festa. Trata-se, como já salientado, de uma festa da cidade.

Em suma, a festa da Uva de Caxias do Sul foi, no passado e é, no presente, uma forma de exaltação coletiva da italianidade, mas não só. Por mais que esteja vinculada ao mercado do turismo (e outros), as simbologias a ela associadas permitem a reatualização constante e a produção de memórias acerca, não somente do passado dos imigrantes italianos na região, mas da própria cidade. É a cidade que também se comemora.

\section{BIBLIOGRAFIA}

ALVIM, Zuleika Maria Forcione. Brava gente! Os italianos em São Paulo 1870- 1920. São Paulo : Brasiliense, 1986.

ARAÚJO, Rita de Cássia Barbosa de. Festas : máscaras do tempo, Recife : Fundação de Cultura Cidade do Recife, 1996.

AZEVEDO, Thales. Os Italianos no Rio Grande do Sul - Cadernos de Pesquisa. Caxias do Sul : EDUCS, 1994. 
BENEDUZI, Luis Fernando. Festa da Uva e política fascista : narrativa de operosidade e resgate da italianidade. Anais do XXVI Simpósio Nacional de História- ANPUH. São Paulo, julho 2011. Disponível no site : http://www.snh2011.anpuh.org/. Acesso em : 30 ago 2012.

DA MATTA, Roberto. 0 que faz o brasil, Brasil ? ,Rio de Janeiro : Rocco ,6a. ed., 1993.

DE BONI, Luis Alberto. "O catolicismo da imigração : do triunfo à crise”. In : A. Lando et alii (org.), Migração \& colonização. Porto Alegre : Mercado Aberto, 1980. pp. 234-255.

ESPEIORIN, Vagner Adílio e POZENATO, Kenia Maria Menegoto. Identidade e retórica em tempo de Festa da uva : a memória recontada pela imprensa regional. Intercom. XXXIII Congresso brasileiro de Ciências da Comunicação. Caxias do Sul, 2 a 6 set 2010. Disponível em : www.intercom.org.br/sis/ 2010. Acesso em : ago 2012

ERBES, Luiz Carlos. A alma de um povo. 7 Décadas da festa da Uva. Caxias do Sul : Maneco, 2000.

GONZÁLEZ, Jorge. Más(+)Cultura(s) - ensayos sobre realidades plurales, Mexico, Consejo Nacional para la Cultura y las Artes,1994.

GROSSELI, Renzo Maria. Vencer ou morrer. Camponeses trentinos (venetos e lombardos) nas florestas brasileiras. Florianópolis : Editora da UFSC, 1987.

HISTORIA da Festa da Uva. Arquivo Histórico da Festa da Uva. Caxias do Sul, 1991.

HALBWACHS, Maurice. A memória coletiva. São Paulo, Vértice, Editora Revista dos Tribunais, 1990.

MAYNARD ARAÚJO, Alceu. Cultura Popular Brasileira, São Paulo : Melhoramentos,1973.

MONTEIRO, Cristiano Sobroza. Negros em terra de italianos : etnografia da migração de moradores da comunidade de remanescentes de quilombo Arnesto Penna Carneiro de Santa Maria-RS,para Caxias do SulRS. Santa Maria. Dissertação de mestrado, PPGCS/UFSM, 2012.

RIBEIRO, Cleodes Maria Piazza Julio. Festa e Identidade. Como se faz a Festa da Uva. Caxias do Sul : EDUCS, 2002.

SANTOS, Miriam de Oliveira. Bendito é o Fruto : Festa da Uva e Identidade Entre os Descendentes de Imigrantes Italianos de Caxias do Sul - RS, Rio de Janeiro, Tese de doutoramento, PPGAS/Museu Nacional, UFRJ, 2004.

SCHMIDT SILVA, Cristina. Viva São Benedito ! - Festa popular e turismo religioso em tempo de globalização, Aparecida : Editora Santuário, 2000.

SCHLEDER, Adriana. Festa Nacional da Uva : uma nova identidade? XXXII Congresso Brasileiro de Ciências da Comunicação. Curitiba, PR, 4 a 7 de setembro 2009. Disponível em : http:// www2.intercom.org.br/navegacaoDetalhe.php?option=trabalho\&id=36595.Acesso em 30 ago 2012. SEYFERTH, Giralda. "Identidade camponesa e identidade étnica (um estudo de caso)". Anuário Antropológico 91. Rio de Janeiro : Tempo Brasileiro, 1993. p. 31-63, 1993.

SILVA, Denise. Construções identitárias de gênero e imigração reveladas pela fotografia. IV Seminário Nacional de Ciência Política- UFRGS. III Fórum de Gênero, Direitos Humanos e Ciadania. Disponível em : www6.ufrgs.br/scnp/4SNCP/FORUM. Acesso em 30 ago 2012.

TEIXEIRA, Sérgio Alves. Os recados das festas. Rio de Janeiro : FUNARTE,1988.

ZANINI, Maria Catarina. Italianidade no Brasil meridional. A construção da identidade étnica na região de Santa Maria-RS. Santa Maria : EdUFSM, 2006. 
ZANINI, Maria Catarina e SANTOS, Miriam de Oliveira. O trabalho como "categoria étnica" : um estudo comparativo da ascensão social de imigrantes italianos e seus descendentes no Rio Grande do Sul (1875-1975). REMHU, Brasília, Ano XVII, n.33, p. 175-196, 2009.

ZOTTIS, Alessandra. Festa da Uva de Caxias do Sul/RS. A memória de uma festa através de seus cartazes. Rosa dos Ventos. Caxias do Sul, vol 1, n.0, 34p, 2009.Disponível em : http://www.ucs.br/ etc/revistas/index.php/rosa\%20dos\%20ventos/

\section{NOTAS}

1. Caxias do Sul está localizada na região serrana do estado, possuindo, segundo dados estatísticos atuais, 439.902 habitantes, numa área de 1.643,9 km² (www.fee.tche,br). A cidade possui importante pólo metal-mecânico.e uma economia bastante diversificada e dinâmica.

2. Segundo Erbes, eram os "colonos teimosos" (2000, p. 15) que não queriam se abrir às novidades.

3. Para Da Matta : "Nas festas da ordem, a ênfase é sempre colocada na ordem, na regularidade, na repetição, na marcha ordeira, no cântico cadenciado, no controle do corpo que, repito, remete à idéia de sacrifício e disciplina, esses dois ingredientes básicos da promessa. Aqui, o mundo é englobado e apresentado pelas posições sociais que a sociedade considera importante. Seu foco é nas autoridades : de Deus, Pátria, Saúde, Educação e Instrução" (1984, p. 85).

4. As outras colônias eram Conde d'Eu (Bento Gonçalves), Princesa Isabel (Garibaldi) e Silveira Martins, na região central do estado.

5. Este foi o tema da Festa da Uva de 1932. Nesta edição (a segunda) já há uma ênfase grande no trabalho e na produção dos imigrantes e seus descendentes.

6. Para o autor: "Em geral, todas essas festas comemoram ou celebram alguma coisa que, supomos, realmente aconteceu. (...) As festas patrocinadas pelo Estado, como as comemorações da Independência, também celebram uma ocorrência real, o nascimento de uma nação, e por isso são eventos paradigmáticos que justificam a importância da data" (DA MATTA, 1993, p. 89).

7. Este jornal circularia em cerca de 36 municípios e teria uma tiragem de cerca de 26 mil exemplares diários (Espeiorin e Pozenato, 2010).

\section{RESUMOS}

Este artigo tem por objetivo apresentar e analisar elementos presentes na Festa da Uva, evento que ocorre bianualmente na cidade de Caxias do Sul (Brasil). Trata-se de uma festa que teve seu início no ano de 1931 e acompanhou vários momentos da história da migração italiana para o Brasil, bem como dialogou constantemente com momentos marcantes da sociedade regional e nacional. Inicialmente uma festa que tinha o objetivo de exibir os produtos dos colonos italianos ligados à vitivinicultura, assumiu ao longo do tempo um papel de mostra econômica local e regional. Nas últimas edições tem reassumido seu papel de festividade comemorativa e revivificadora da italianidade local desempenhando um importante papel nas construções mnemônicas da imigração italiana para a região serrana do estado do rio Grande do Sul, iniciada em 1875. 
Cet article a pour but de présenter et d'analyser les éléments présents dans la Fête de la Grappe, un événement qui a lieu tous les deux ans dans la ville de Caxias do Sul (Brésil). C'est une célébration qui a débuté en 1931 ; elle a connu plusieurs étapes dans l'histoire de l'immigration italienne au Brésil et s'inscrit dans la société régionale et nationale. Au départ, le but était de présenter les produits de colons italiens liés à la viticulture, puis, au fil du temps, c'est devenu un spectacle à caractère local et régional, avec une dimension économique. A présent, depuis quelques années, la fête célèbre l'italianité. Elle joue un rôle important dans la construction mnémonique de l'immigration italienne vers les hauts plateaux de l'Etat de Rio Grande do Sul, qui a débuté en 1875 .

\section{ÍNDICE}

Mots-clés: Fête du Grappe, l'identité, l'immigration italienne, mémoire, Caxias do Sul Palavras-chave: Festa da Uva, Identidade, Imigração italiana, memória, Caxias do Sul

\section{AUTORES}

\section{MARIA CATARINA C. ZANINI}

Universidade Federal de Santa Maria

zanini.ufsm[at]gmail.com

\section{MIRIAM DE OLIVEIRA SANTOS}

Universidade Federal Rural do Rio de Janeiro

mirsantos[at]uol.com.br 